\title{
Teorizando a imagem: pensar sobre representação e a corporificação da iconografia medieval
}

\author{
Teorizando la imagen: pensar sobre representación y la corporificación de \\ la iconografía medieval
Theorizing image: thinking about representation and the embodiment of medieval iconography

\author{
Amanda Basilio Santos ${ }^{1}$ \\ Ronaldo Bernardino Colvero
}

\begin{abstract}
Resumo
Este artigo explora questões teóricas concernentes ao estudo da iconografia medieval. Abrimos o texto com um preâmbulo sobre os estudos com fontes imagéticas na historiografia. Após pensarmos nestas questões, nos propomos a debater, ainda que laconicamente, os aspectos específicos as fontes iconográficas medievais enquanto fonte histórica, tecendo relações entre a visibilidade, materialidade e imaterialidade da iconografia medieval. A partir desta discussão, iremos deliberar sobre os usos conceituais para o estudo desta fonte histórica, focando, principalmente, em dois conceitos: primeiramente, o conceito de representação, tal como proposto por Roger Chartier, e o conceito de imagem-corpo, estabelecido por Jean-Claude Schmidt.
\end{abstract}

Palavras-Chave: Iconografia; Medievo; Teoria; Conceito

\section{Resumen}

Este artículo explora cuestiones teóricas concernientes al estudio de la iconografía medieval. Abrimos el texto con un preámbulo sobre los estudios con fuentes imagéticas en la historiografía. Después de pensar en estas cuestiones, nos proponemos a debatir, aunque laicamente, los aspectos específicos a las fuentes iconográficas medievales como fuente histórica, tejiendo relaciones entre la visibilidad, la materialidad e inmaterialidad de la iconografía medieval. A partir de esta discusión, vamos a deliberar sobre los usos conceptuales para el estudio de esta fuente histórica, enfocándose principalmente en dos conceptos: primero, el concepto de representación, tal como propuesto por Roger Chartier, y el concepto de imagen-cuerpo, establecido por Jean-Claude Schmidt.

Palabras clave: Iconografía; Edad Media; Teoría; Concepto

\begin{abstract}
This article explores theoretical questions concerning the study of medieval iconography. We open the text with a preamble on studies with imagery sources in historiography. After thinking about these questions, we propose to discuss, although laconically, specific aspects of medieval iconographic sources as a historical source, linking the visibility, materiality and immateriality of medieval iconography. From this discussion, we will deliberate on the conceptual uses for the study of this historical source, focusing mainly on two concepts: first, the concept of representation, as proposed by Roger Chartier, and the concept of body image, established by Jean-Claude Schmidt.

\footnotetext{
${ }^{1}$ Doutoranda em História (PPGH - UFRGS); Mestra em História (PPGH - UFPEL); Mestra em Memória Social e Patrimônio Cultural (PPGMP - UFPEL); Especialista em Artes (PPGA - UFPEL). Membro do LAPI (Laboratório de Política e Imagem - UFPEL); Membro do NEM (Núcleo de Estudos Medievais - UFRGS). Contato: amanda_hatsh@yahoo.com.br.

2 Doutor em História pela Pontifícia Universidade Católica do Rio Grande do Sul. Professor adjunto na Universidade Federal do Pampa (São Borja) - Professor do Pós-Graduação de Políticas Públicas da Universidade Federal do Pampa e do Pós-Graduação em Memória Social e Patrimônio da Universidade Federal de Pelotas. Contato: rbcolvero@gmail.com
} 
Keywords: Iconography; Medieval; Theory; Concept

\section{Estudos de imagem: um caminho historiográfico}

Os estudos com fontes iconográficas são objetos relativamente novos para os historiadores. Com o advento dos questionamentos dos paradigmas historiográficos levantados pelos historiadores que fundaram a Escola dos Annales em 1929, o modo de fazer e pensar a disciplina modificou-se, ampliando-se as temáticas de pesquisa, assim como as fontes para tal empreendimento (BURKE, 1991). Desta forma a preferência da metodologia positivista pelos documentos escritos, de cunho oficial e centralizado em eventos, numa narrativa histórica, foi questionado, e proposto um novo modelo, que permitisse estudar novos campos da vida social, em comunhão com conceitos e metodologias adotados pela aproximação pluridisciplinar. Aproximando a História das outras disciplinas sociais rompeuse barreiras, abrindo um leque de possibilidades de questionamentos e abordagens, com um enfoque na troca de experiências entre as disciplinas propostas pelos fundadores do periódico dos Annales, conhecido como a Primeira Geração, tendo como principais expoentes Marc Bloch e Lucien Febvre. Trocou-se o enfoque do evento pontual para o estudo da Longa Duração (la longue durée), mudando-se, portanto, o tratamento do tempo dentro da historiografia. Nesta percepção a compreensão das sociedades só se dá no estudo contínuo, no acompanhamento das continuidades, não das mudanças, ou revoluções.

Novas abordagens historiográficas focaram-se nos modelos marxista e pelo modelo de uma História Total, proposta por Fernand Braudell, já na Segunda Geração da Escola. Porém estes modelos entraram em crise, no que se denominou como a "crise dos paradigmas", fortemente marcada pela experiência da globalização, vivenciada também pelos historiadores. Deste modo modelos baseados em continuidades e em busca de modelos já não satisfaziam mais em frente a grande diversidade que é latente nos dias atuais. Novas correntes historiográficas surgiram, novos conceitos foram discutidos e uma História preocupadas com a diversidade e a cultura foi se formando. A Nova História Cultural (NHC) veio saciar a necessidade de discutir estes modelos explicativos de uma realidade que se pretende homogênea, reconhecendo-se as especificidades das sociedades e dos homens diante dos processos históricos. Iniciando-se na década de 80 , tal vertente historiográfica gera divisões quanto à sua origem, sendo que alguns historiadores lhe dizem herdeira de uma visão do século XVIII, através do conceito de Zeitgeist, enquanto outros a colocam como vinculada as 
tradições dos Annales, principalmente a vertente da História das Mentalidades (Histoire des mentalités).

A NHC retira a Cultura de seu papel de reflexo de uma infraestrutura, ou como propriedade de uma elite que se impõe através do domínio dos meios culturais sobre o restante social, sendo assim:

A dita Nova História Cultural propõe uma nova maneira de se trabalhar a cultura, não no sentido de se construir uma história do pensamento, ou uma história intelectual que estudaria as grandes correntes de idéias e seus nomes mais expressivos. Trata-se de pensar a cultura como um conjunto de significados partilhados e construídos pelos homens para explicar o mundo. O que importará, segundo a História Cultural, será conduzir a análise num percurso que vai do significante para o significado, do veículo para a mensagem e, desta, para os grupos sociais que a produzem ou que se apropriam dela (SOUSA, 2005, pág. 2)

Os historiadores passaram com mais veemência a preocupar-se com os significados simbólicos da cultura, e a arte, ou os objetos visuais, que passaram a ser parte importante da produção historiográfica. Os estudos dos objetos visuais passam a ganhar espaço dentro da historiografia para os objetivos desta nova linha teórica/metodológica. É nestas circunstâncias que a imagem passa a ser objeto de interesse entre os historiadores, e é este o enfoque de nossa discussão, principalmente do objeto iconográfico medieval e suas especificidades.

Ainda assim, mesmo nos dias atuais, a utilização de imagens enquanto fontes históricas são muitas vezes feito quando há escassez documental de outra natureza para a pesquisa historiográfica, seja por uma formação que privilegia a documentação escrita, por uma questão de tradição e segurança metodológica, ou por ser um objeto considerado como suporte de outros, sendo muito comum termos imagens apenas "ilustrando" a informação referenciada em outra fonte, ou seja, a imagem auxilia a dar corpo e veracidade a uma fonte, mas não é a fonte que se baste. Desta forma por um longo período de tempo o estudo a partir de imagens esteve restrito a disciplina de História da Arte. Segundo Silva:

Essa charmosa segregação da visibilidade no exclusivo espaço da História da Arte se relaciona com vastas tradições que se acostumaram a associar Pesquisa Histórica a Imagens apenas através desse gênero específico ou num universo de "carência documental", quando se aborda sociedades cujas fontes escritas são de difícil ou impossível acesso. Não se trata de menosprezar a vital importância da História da Arte para o Conhecimento Histórico como um todo nem de negligenciar os limites documentais efetivos que cada pesquisador enfrenta. Preocupa-nos a transformação do trabalho com o visual em tarefa exclusiva de alguns especialistas, sem um efetivo esforço dos Historiadores em geral para integrar tais objetos às suas discussões sobre o social. (SILVA, ago-dez/91 a jan-jul/92, pág. 117-118)

Esta abordagem, de uma imagem suporte, tem se modificado, ao passo que muitos historiadores têm visto o potencial da iconografia para a compreensão do período em que se 
insere. Temos alguns autores basilares para estes estudos como David Freedberg e Hans Belting. Em sua obra intitulada The Power of Images, David propõe o estudo de todo tipo de imagem, e não apenas aquelas, consideradas pelo seu valor estético, como artísticas. Esta proposta causou um grande salto nos estudos históricos, distanciando de uma História da Arte clássica, onde as grandes obras, de grandes artistas, eram valorizadas em detrimentos de outras produções visuais. Sua principal contribuição é o de valorizar o efeito que as imagens produzem nas pessoas e, portanto, o seu papel ativo dentro da sociedade. Esta perspectiva causou muito impacto e o estudo das imagens tornou-se também o estudo da recepção do objeto visual no social, atribuindo-lhe funções e capacidade de interação.

A contribuição de Hans Belting está no destaque dado ao conteúdo que compõe as imagens. Para ele uma imagem é repleta de significados culturais, composta de crenças, medos e sentimentos da época de sua produção. Esta visão também é partilhada por um dos principais historiadores da iconografia medieval, Jean-Claude Schmitt. A imagem a partir da visão destes autores transcende seu valor estético, o que influenciou fortemente o afastamento dos historiadores da importância da forma das representações artísticas para a análise.

Um autor que influenciou fortemente a ideia da "Cultura Visual" foi W. J. T. Mitchell, que na década de 90 ministrava uma disciplina com este nome, insistindo no argumento de terminar com as divisões entre alta e baixa cultura dentro das artes, incentivando o estudo e análise de todas as mídias visuais e sua recepção, assim sendo importando a compreensão dos sistemas de representação que as pessoas fazem do mundo através do visual, definindo também as diferenças entre a produção visual e textual, destacando assim a especificidade de estudar fontes iconográficas.

O reconhecimento da dinâmica e da diversidade das sociedades destacada pela NHC tornou a imagem um importante componente de análise para o estudo do poder e seus mecanismos de manutenção social:

Essa postura, que compreende o processo social como dinâmico e com múltiplas dimensões, abre espaço para que a História tome como objeto de estudo as formas de produção de sentido. O pressuposto de seu tratamento é compreender os processos de produção de sentido como processos sociais. Os significados não são tomados como dados, mas como construção cultural. Isso abre um campo para o estudo dos diversos textos e práticas culturais, admitindo que a sociedade se organiza, também, a partir do confronto de discursos e leituras de textos de qualquer natureza - verbal escrito, oral ou visual. É nesse terreno que se estabelecem as disputas simbólicas como disputas sociais. Conforme adverte Georges Ballandier, 'o poder só se realiza e se conserva pela produção de imagens, pela manipulação de símbolos', pois, simplesmente pela força, sua existência seria sempre ameaçada. 2 Dito isso, pode-se compreender a importância do estudo da produção artística como fonte de discursos que se relacionam com a vida em sociedade. (KNAUSS, 2006, pág. 99) 
O estudo dos símbolos e de seu poder na sociedade também afastou o historiador da preocupação estética para dar atenção ao conteúdo e sua recepção pelo corpo social. Esta forma de análise das imagens diferencia-se fundamentalmente dos modos tradicionais de "fazer história da arte" tal qual definido por Henri Zerner em seu livro "História: Novas Abordagens", no qual ele destaca que tradicionalmente se fazia o estudo das imagens a procura da biografia do artista e de seus valores estéticos, fazendo o inventário das obras artísticas (ROCHA, 2011).

\section{Imagética medieval e suas funções: corporificação e/ou representação?}

O estudo da iconografia medieval começa nos conceitos que utilizamos para fazê-lo e pelo modo como nos debruçamos sobre o nosso objeto, levando em consideração a sua natureza e especificidades. Para estudar as fontes iconográficas medievais temos de ter em mente suas particularidades e aspectos multifacetários, que tocam diferentes âmbitos, percorrendo desde a produção de objetos visuais até os seus usos e apropriações. No vocabulário medieval já temos presentes tanto imagem (imago) quanto arte (ars) e suas atribuições eram bem definidas. A imago pertencia ao produto final, ligado à sua recepção e aos seus usos, enquanto ars está circunscrito no processo de produção.

O fato da arte estar ligada ao ofício diferencia fundamentalmente a relação que temos hoje com a ideia da produção artística como sendo algo de provém da inspiração e liberdade do próprio artista. Pois, no período medieval, ela está ligada à capacidade de produção, de habilidade técnica no momento de sua manufatura.

Quanto à questão da natureza da imagem medieval, para além da visibilidade, esta deve ser vista com o seu suporte e com relação aos materiais que lhe dão visibilidade, pois estes transmitem e definem importância e significado, demonstrando a riqueza e a beleza, ornando as imagens com seus triunfos materiais. Há também a preocupação com o imaterial que deve ser atingido através da imagem:

\footnotetext{
Por um lado, há certamente uma preocupação estética: com o brilho e a riqueza da obra - duas faces de uma mesma moeda. Mas também há, de outro lado, a preocupação que esse objeto admirado não seja em vão, que ele tenha uma função e que a desempenhe bem. E essa função, a mais nobre de todas (à altura da nobre obra), seria a de elevação do espectador até a realidade imaterial, ao mundo divino (PEREIRA, 2010, p. 2-3)
}

Assim sendo, há uma função de descortinação de um mundo imaterial que deve ser atingido por meio da intermediação visual. Porém, este mundo intangível é conhecido pela 
materialidade da imagem. Neste sentido, um autor fundamental nos estudos iconográficos medievais é Jérôme Baschet, e seu conceito de "imagem-objeto". Para este autor, a imagem não pode ser dissassociada das questões materiais, destacando que no medievo as imagens acabam:

Dando lugar a usos, manipulações, ritos; um objeto que se esconde e se revela, que se veste e se despe, que às vezes se beija ou se come (pensemos nas hóstias que trazem muitas vezes imagens); um objeto que demanda orações, respondendo às vezes por gestos ou pela emissão de humores (sangue, água, óleo...), reclamando também dons materiais. (BASCHET, 1996, p. 8. Trad. Maria Cristina Pereira)

Tal conceito nos fornece uma complexa forma de aproximação e interpretação da imagem medieval, sobrepujando os limites da própria imagem, e a inserindo em um mundo repleto de funções e usos, escapando da ideia de contemplação passiva diante das imagens, e a incorporando junto ao mundo material que lhes dá visibilidade. Assim sendo, a imagemobjeto auxilia na análise iconográfica pois define:

A expressão tem a vantagem de recobrir dois casos distintos, quer a imagem constitua por si só um objeto dando lugar a várias utilizações (uma estátuarelicário, por exemplo), quer ela aderindo a um objeto ou a uma arquitetura possuidora de funções (neste caso, o traço de união, que parece ligar duas realidades separadas, deverá ser considerado sobretudo como o sinal de unidade dos dois aspectos de uma mesma coisa). (BASCHET, 1996, p. 11-12. Trad. Maria Cristina Pereira)

Durante o medievo, o material e o visual trabalhavam de modo bilateral, havendo momentos em que estes aspectos trabalhavam em favor do outro. Podemos ver isso ocorrer, por exemplo, na Catedral de Chartres, onde as pinturas murais que sobreviveram às intempéries do tempo indicam uma paleta de cores (amarelo ocre) que se une a uma esquematização de intercalações com a tinta branca, que não possui fins alegóricos, mas sim arquitetônicos. Sendo que, neste caso, a pintura trabalha para engrandecer o aspecto estrutural, sendo disposta de modo estratégico para realçar os elementos arquitetônicos:

Os elementos brancos enfatizavam a articulação da estrutura durante a criação de uma pseudo-estrutura delicada das nervuras demasiado ténue em si para suportar o peso das pedras em torno dele. Não há dúvida, portanto, que esta pintura não é mera decoração, mas é deliberadamente 'arquitectónica' tanto reforçando quanto sensibilizando para a ordem e lógica da alvenaria.. ${ }^{3}$ (BALL, 2009, p. 54. Tradução da autora)

\footnotetext{
${ }^{3}$ Original: "The white elements emphasized the articulation of the structure while creating a delicate pseudoskeleton of ribs too tenuous in itself to carry the weight of the stones around it. There is no doubt, then, that this paintwork is not mere decoration but is deliberately 'architectural' both reinforcing and sensitively elaborating the order and logic of the masonry."
} 
Temos sempre de considerar a intercambialidade existente entre os elementos que compõem uma igreja, compreendendo a natureza de um sistema que possui diversas regras de funcionamento para que seja compreensível. Mas não por esta razão torna-se um sistema enrijecido, submetido às funções tão facilmente determináveis e universais, como naquele modelo trabalhado na História da Arte clássica. No medievo, a escultura era parte fundamental da ornamentação das igrejas, tanto no período românico quanto no gótico, de modo que funcionava em relação a arquitetura, sendo que esta última a condicionava (NIEHR, 2010, p. 119).

Uma igreja medieval funcionava por meio de uma união de sistemas e sentidos, a arquitetura e a imagem produzem sensações, sonoridades e experiências. Portanto, a noção de uma imagem contemplativa e de um local onde se frequenta de modo passivo não se aplicam. Seus elementos se retroalimentam e completam, portanto, a imagem, a matéria, são ao mesmo tempo visibilidade, sensação, sons ${ }^{4}$.

Voltamos à importância da união dos diferentes elementos que compõem o grande produto que é uma igreja medieval, estudando-os em conjunto. Pois, como destaca Klaus Niehr sobre a escultura medieval e os estudiosos da mesma:

Os estudos têm, no entanto, a tendência de analisar os aspectos desta história em isolamento. Analisou-se o desenvolvimento estilístico, as funções religiosas e litúrgicas, iconografia, e como as narrativas pictóricas correspondem ou divergem a partir de fontes textuais. Cada uma dessas abordagens é útil, mas destacar apenas um ou dois aspectos para o estudo não pode lançar as bases para um entendimento completo de escultura arquitetônica. Esculturas respondem a uma ampla gama de exigências, sendo que todos têm grande importância para sua aparência exterior, e os estudiosos devem estar em sintonia com os vários fatores em jogo. ${ }^{5}$ (NIEHR, 2010, p. 119. Tradução da autora)

Nos estudos de representação, normalmente, há uma profusão de análises de elementos considerados em separado de seu conjunto iconográfico. Compreendendo o sistema ornamentativo e construtivo de uma igreja medieval, nos parece, inviável esta abordagem para uma interpretação satisfatória.

\footnotetext{
${ }^{4}$ Sobre a sonoridade e sua relação com a arquitetura e a iconografia no medieval ver a obra Resounding Images: Medieval Intersections of Art, Music, and Sound, editado por Susan Boynton e Diane J. Reilly (2015).

${ }^{5}$ Original: "Scholarship has nevertheless tended to examine aspects of this history in isolation. It has looked at stylistic development, religious and liturgical functions, iconography, and how pictorial narratives correspond or diverge from textual sources. Each of these approaches is useful, but singling out only one or two for study cannot lay the foundation for a thorough understanding of architectural sculpture. Sculptures respond to a wide range of demands, all of which have great importance for their outward appearance, and scholars must be attuned to the various factors at play".
} 
Ao interpretar a imagem, ligando seu significado ao seu mundo material é essencial levar em consideração que esta não será algo de admiração contemplativa, mas que ela possui agência, que se concretiza através de variados fatores, como: materialidade, conteúdo, estética, disposição espacial e público alvo. A união destes fatores permite uma compreensão da imagem no medievo muito mais vasta, mas que dificilmente se alcança através de um único viés analítico, ou de um único conceito de base.

Faremos nesta seção, de modo muito breve, uma discussão sobre os três principais conceitos da atualidade na historiografia para lidar com as imagens medievais (imagem-coisa, imagem-objeto e imagem-corpo), pensando também um conceito muito utilizado em trabalhos de Cultura Visual contemporânea: representação. Nos dedicaremos mais atentamente a discussão sobre o uso do conceito de imagem-corpo ou de representação, segundo o proposto Roger Chartier, para pensarmos modos de análise dos objetos visuais na Idade Média.

Iniciaremos pelo conceito que não foi pensado voltado à medievalística. No livro de Roger Chartier, À beira da falésia: a história entre incertezas e inquietudes (2002), temos o capítulo dois dedicado ao conceito de representação, intitulado $O$ mundo como representação. Neste capítulo ele define o conceito salientando o seu caráter ambíguo, pois a representação evoca a ausência tornando-a visível, trata-se da presença de algo ausente, pois a representação não se trata do objeto em si, mas sim de uma imagem capaz de remontar a sua memória, e ao mesmo tempo a representação é caracterizada por criar uma presença (CHARTIER, 2002).

Representação é um conceito que trabalha em sintonia com muitos outros, tais quais mito, memória, imaginário, e sua utilização ampliou-se muito cunhados no espectro da História Cultural. Todavia, como o próprio Chartier (1990) destaca, embora muito se utilize deste conceito, não apenas no campo historiográfico, este amplo uso não foi acompanhado de reflexões mais profundas sobre sua definição e/ou significações. Se faz então necessário destacar que o conceito de representação, assim como os próprios fenômenos definidos como representações, não é compreendido de um único modo sempre. A representação está sujeita às apropriações que serão feitas a partir dela, sendo a apropriação a transformação sofrida através dos tempos e locais, o modo como os agentes históricos se apropriam que nem sempre condiz com a intenção de sua produção. Enfim temos as práticas, que nem sempre seguem os discursos ou as representações atribuídas a elas. 
Embora haja diferentes usos para a palavra representação, segundo Makawiecky, há um ponto em comum aos usos desta palavra:

\begin{abstract}
Representação é um processo pelo qual institui-se um representante que, em certo contexto limitado, tomará o lugar de quem representa. Assim uma cena da cidade de Florianópolis em uma obra plástica que evoca Florianópolis, por exemplo, tomará o lugar da cidade, naquele contexto limitado. Os significados da obra tomam o lugar da cidade, não de forma idêntica, porém análoga, através das atribuições de significados (MAKAWIECKY, 2003, p.4)
\end{abstract}

Representação, assim, se colocou como um conceito fundamental para os estudos de História Cultural, que tem como objetivo, segundo Chartier "identificar o modo como em diferentes lugares e momentos uma determinada realidade social é construída, pensada, dada a ler" (CHARTIER, 1990, p. 17).

Logo Chartier tornou-se um dos historiadores mais citados em pesquisas acadêmicas, incluindo o Brasil, sendo aqui um dos historiadores estrangeiros mais recorrente (CARVALHO, 2005, p. 144).

$\mathrm{Na}$ medievalística, suas conceituações também tiveram influência consideráveis. Temos, por exemplo, o livro editado por Julia Bray (2006), intitulado Writingand Representation in Medieval Islam: Muslim Horizons. Composto por seis artigos, temos aqui um bom exemplo dos usos da História Cultural pelos medievalistas, assim como o emprego do conceito de representação para a compreensão do social. Saindo das fontes escritas e se aproximando do mundo da cultura material e iconográfica temos o livro de Nigel Saul (2009), intitulado English Church Monuments in the Middle Ages: History and Representation, onde aborda a importância da representação pessoal e social através das artes, concentrando-se principalmente na arte escultórica.

Todavia estes trabalhos supracitados, que são ancorados no conceito de representação, não trabalham com a análise iconográfica propriamente dita, mesmo na pesquisa de Saul, temos um trabalho de cunho social, onde a arte é um veículo para a análise, mas não se constitui enquanto uma pesquisa de iconografia.

O trabalho do historiador Jean-Claude Schmitt (2007), voltado para as imagens medievais, destaca que há diferenças basilares entre a nossa produção de imagens e, portanto, de seu impacto. Ele destaca que vivemos em uma época de imagens móveis (cinema, televisão, etc) em contraposição as imagens imóveis produzidas pelos medievais, há no medievo uma relação distinta entre figura e o fundo, diferente dos usos da perspectiva ao qual 
estamos acostumados, e principalmente a imagem medieval não "representa", ela "corporifica" (SCHMITT, 2006). Deste modo, pensarmos na ideia de representação, mesmo sendo elevada a evocação mimética, tornando-se presença de uma ausência, não qualifica o fenômeno de recepção das imagens medievais, onde a imagem é corporificação real do retratado, ela é presença material do divino, e não uma representação do mesmo, ou uma forma de evocar uma ausência.

A complexidade que o conceito de imagem-corpo atribui para as imagens medievais, pode ser compreendido pelo estudo de Schmitt, onde afirma que a "imagem medieval se impõe como uma aparição, entra no visível, torna-se sensível” (p. 16), esta sensibilidade está condicionada a um contexto macro (da cristandade) e a um contexto micro (realidade das paróquias, contexto sociocultural, manipulação de imagens e estabelecimento de cultos e seleções). Estes dois universos, que podem gerar apropriações imagéticas antagônicas, interferem no significado das imagens e nas funções desempenhadas pelas mesmas. Deste modo, nos encaminhamos para a compreensão dos significados sociais do corpo e das formas de corporeidade no medievo, pois "olhar as santas imagens não era somente uma operação dos sentidos [...], mas um ato de imaginatio, do qual se esperava que pudesse transformar a carne e, mais ainda, a alma dos seres" (SCHMITT, 2007, 368). A imagem, que é corpo de um mundo intangível, afeta o mundo físico, dado seu meio de apropriação e o status atribuídos aos usos das imagens. Pensar na categoria da corporeidade, que extrapola a moldura da imagem, e configura seus efeitos sociais, nos força a suplantar o conceito de representação, buscando uma ferramenta analítica que possa dar conta da imagem medieval enquanto um fenômeno social específico, e considerando uma recepção imagética muito distinta da nossa.

Resumindo, temos que compreender os processos de recepção da imagem medieval de modo diferente. Pois, por meio da corporificação, da presentificação real, ela causa reações distintas pelo seu poder de tornar presente uma ausência, personificando a santidade através da sua visualização imagética, uma característica destacada por David Freedberg em sua obra The Power of Images (1992), livro no qual faz críticas severas a História da Arte por não levar em consideração em suas análises o poder que as imagens possuem e a relação de sua recepção pelas pessoas que entram em contato com elas. Nesta linha devemos destacar o conceito de imagem-corpo, elaborado por Jean-Claude Schmitt, e que destaca o fato das imagens possuírem poder de gerar reações, tanto de amor quanto de ódio:

Em vários manuscritos, as miniaturas que figuram o Diabo foram raspadas, como se os leitores tivessem pretendido apagar para sempre o olhar malévolo que os 
ameaçava. Algumas imagens eram consideradas como 'pessoas', não como a imagem de São Tiago, mas como o próprio São Tiago. Tais imagens não eram vistas como inertes, aos fiéis que se dirigiam a elas pareciam responder fazendo um sinal com os olhos ou com a cabeça, chorando, sangrando, as vezes até falando. Proponho chamá-las de 'imagem-corpo'. Nem todas as imagens estavam assim dotadas de uma aparência de corporeidade, de vida e de poder milagroso. Mas não se podia prejulgar a capacidade de alguma delas tornar-se imagem-corpo, pois tudo era função das expectativas que a imagem era capaz de satisfazer e dos interesses econômicos, políticos, dinásticos, etc., aos quais a posse de uma imagem milagroso podia localmente servir (SCHMITT, 2006, pág. 599)

Podemos ver como certas imagens suscitam reações fortes nos seus expectadores, que estão ligados a elas por sistemas de crenças e por sistemas simbólicos. Mas há aspectos da imagem medieval ligados ao seu uso, a sua materialidade e o modo como ela se insere na sociedade, o que Jérôme Baschet define como "imagem-objeto". Para o autor as imagens estão intrinsecamente ligadas ao seu papel nos cultos, a sua utilização ritual, que lhes confere valor simbólico, as imagens neste aspecto tornam-se instrumentos da difusão dos cultos, são assim funcionais em sua essência: "Não há na Idade Média uma imagem que seja pura representação. Nós lidamos muitas vezes com um objeto, que resulta em utilizações, manipulações e a rituais" "6 (BASCHET, 1996, pág. 8). Podemos ver, portanto, uma outra visão da imagem, aquela que não gera apenas reações, mas que é manipulado, utilizado, incorporado nas práticas sociais e assim imbuído de significados e de importância. Como é destacado pelo medievalista supracitado, não é pura representação.

Por fim, temos o conceito proposto por Jean-Claude Bonne, imagem-coisa. Para este autor há imagens que não intencionam a representação simbólica de nada, destacando-se neste aspecto o valor ornamental da imagem e seu aspecto funcional:

O ornamental se caracteriza por ser, sobretudo, muito mais que um tipo de forma, mas um modo de funcionamento das formas, de maneira que podemos falar em 'ato ornamental'. Ele é a capacidade que as formas possuem de assumir diversas funções (BONNE, 1996, pp. 215-216), de fazer sistema e agir na imagem e/ou sobre os outros motivos de diversas maneiras: modulando, graduando, ritmando, hierarquizando, dentre outras. O ornamental não se desenvolve à margem ou ao lado da representação, mas se articula com ela e participa de sua estrutura. Esse ato ornamental possui uma transversalidade, a capacidade de agir sobre os mais diversos elementos de uma imagem, inclusive os iconográficos, em diversos níveis de articulação (SANTOS, 2014, pág. 4)

Por este viés a estética entra em evidência e ela pode revelar diversos aspectos da imagem que antecedem a recepção ou o uso, de modo que devemos pensar na importância do momento da produção. O sentido estético no medievo, a intenção do belo, transpõe os limites

\footnotetext{
${ }^{6}$ Original: "Il n'y a pas d'image au Moyen Age qui soit une pure représentation. On a le plus souvent affaire à un objet, donnant lieu à des usages, des manipulations, des rites".
} 
gerados pela teoria estética iniciada no século XVIII, no medievo ela inclui uma "realidade moral e psicológica para o homem da Idade Média [...] ampliando o interesse estético para o campo da beleza não sensível" (ECO, 1989, p. 16), e ao fazer esta extensão os medievais teciam relações com as questões concernentes à beleza sensível e natural.

Compreender a função - em um sentido único - da arte medieval ou da imago medieval se torna algo ingrato ao nos depararmos com a diversidade de locais em que é utilizada e com a diversidade de fins. Mesmo se estudarmos apenas pinturas murais, para delimitarmos um objeto específico, estaremos diante da exposição de diversas temáticas, com as mais variadas funções, e com uma diversidade de estilos que varia de regiões para regiões (quando não dentro de uma mesma região), de período, e dependendo das preferências dos patronos.

Em 599 d.C. o Papa Gregório Magno escreveu uma carta ao Bispo Sereno de Marselha ${ }^{7}$ que passou a influenciar profundamente a ideia da função da arte medieval que temos até os dias atuais (BESANÇON, 2006, p. 32). Nesta carta ele destaca a função didática do uso das imagens, permitindo à massa de iletrados compreender a doutrina, ensinando-os através de imagens o que eles não podem ler. Embora na própria carta ele aponte outras funções para as imagens - elas servem de lembrança dos dogmas, e possuem um poder sobre os fiéis, pois cumprem um papel de sensibilização destes e fazem com que eles se arrependam de seus pecados - o papel didático acabou se sobrepondo na literatura aos outros, colocando a iconografia medieval como a Bíblia dos iletrados (SCHMITT, 2006), pensamento propagado na historiografia apoiada através da obra do historiador da arte, Émile Mâle ${ }^{8}$. No entanto, se a função fosse puramente ensinar a doutrina aos fiéis não haveria função para a abundância de imagens circunscritas nos coros e na abside das igrejas, locais de acesso restrito do clero, que ao menos na sua massiva maioria era letrado.

Jean-Claude Schmitt destaca que a primeira função das imagens cristãs é a de ser um meio de adoração a Deus:

Evitemos, contudo, simplificar a enumeração das funções das imagens cristãs. É preciso prestar atenção por exemplo na localização dos programas pintados, que muitas vezes concerniam mais o coro da igreja, reservado ao clero, do que a nave, onde ficavam acantonados os leigos: a instrução destes, separados dos clérigos por uma cancela, não dependia sempre das imagens. Deve-se também levar em conta a pouca visibilidade de muitas destas imagens, em primeiro lugar dos vitrais, que não

\footnotetext{
${ }^{7}$ GREGORIO MAGNO, Epistulae ad Serenus, XI, 13, (Patrologia Latina 77, col. 1128-1130).

${ }^{8}$ Sobre esta questão ver: MÂLE, Émile. L'art religieux au XIIIe siècle en France. Étude sur l'iconographie du Moyen Âge et ses sources d'inspiration. Paris: Armand Colin, 1910.
} 
podiam ser decifrados em detalhe. Para um bispo como para os cônegos do capítulo, para uma comunidade de religiosos, o magistrado de uma cidade ou ainda um príncipe, o fato de construir uma igreja e decorar toda a superfície de suas paredes com pinturas, vitrais e esculturas, de coroar altares com retábulos pintados ou esculpidos, de se munir de manuscritos iluminados, visavam a outros fins além da instrução dos iletrados. Era primeiramente um meio de cumprir um contrato feito com Deus, sacrificando-lhe consideráveis somas de dinheiro, necessárias a escolha dos materiais mais preciosos e do pagamento dos salários dos pintores, escultores, mestres vidreiros, ourives (SCHMITT, 2006, pág. 599-600)

Temos, portanto, de levar em consideração a intenção quando fazemos a análise iconográfica, lembrando a função que esta imagem tinha, pois elas não eram apenas figurativas. Compreendendo os variados aspectos intencionais e aplicações da iconografia medieval, podemos compreender a razão pela qual o conceito de representação se apresenta de modo deficitário para explicar este fenômeno visual e material.

O mesmo papa citado também destacou e sancionou, o uso de imagens para auxílio de conversão de pagãos ao cristianismo. Este fato fica explícito em uma carta, Epistola ad Mellitum $^{9}$, do papa ao bispo de Londres, hoje conhecido como São Melito de Cantuária, onde ele afirma que as conversões seriam mais fáceis se as pessoas pudessem manter certos elementos externos de suas tradições, fazendo desta forma uma conversão mais branda, onde as imagens tem papel importante tanto na implementação de uma nova crença, quanto na preservação de traços da antiga.

As obras e sua ornamentação serviam para interceder pelo pecador, para lhe redimir os pecados feitos através do financiamento de obras piedosas. Esta necessidade de construção de igrejas também pertence a um momento muito particular do século $\mathrm{X}$, pois estava vinculado à crença de que na virada do século se daria a volta de Jesus Cristo. A construção de igrejas não seria apenas uma forma de louvor, mas uma maneira de assegurar um fim favorável no momento do Juízo Final. Esta crença trouxe grandes vantagens econômicas ao mundo feudal, pois este frenesi construtivo gerou um grande escoamento de riquezas que antes encontravamse concentradas e guardadas em mãos de muitos poucos. Graças as construções estas riquezas se transformaram em compras e transporte de materiais, artefatos para ornamentação e em contratação de mão de obra. A estes campos de construção Jacques Le Goff denominou como possivelmente a primeira e única empresa medieval (LE GOFF, 2005)

\footnotetext{
${ }^{9}$ Esta carta pode ser lida na obra de Bede, "Historia ecclesiastica gentis Anglorum", disponível em < https://archive.org/details/bedehistoriaecc00bedegoog>, acessado pela última vez em 13 de março de 2018.
} 
Saindo destas funções mais pessoais, a construção era uma forma de demonstração, afirmação e manutenção de poder e força. Ao construir uma igreja e um castelo o nobre que os financiava estava demonstrando as suas próprias condições financeiras, e quanto mais suntuosa estas fossem, maior seria as suas capacidades econômicas, transformando-se também em uma forma de ostentação. Muitos nobres viajavam para conhecer as igrejas circundantes antes de decidir como pedir que fosse construída aquela sob seu patronato, desejando construir uma igreja mais elaborada na região próxima a sua área de influência. Como Malcolm Thurlby diz, ao construir uma igreja e um castelo é assegurado o poder temporal e espiritual e ao mesmo tempo símbolos da cultura se estabelecem na região onde há estas construções (THURLBY, 2002). As imagens também possuem caráter prático ao passo em que podem ser manipuladas em ritos, como uma cruz cerimonial, sendo incorporada diretamente nos sistemas de ritos.

Considerar estas múltiplas funções, rituais, políticas, sociais, religiosas e de cunho pessoal pelo campo do conceito de representação acaba por minorar o papel ativo da iconográfica medieval dentro do âmbito social de seu desenvolvimento. As variadas apropriações da imagem, em profunda simbiose com sua materialidade, pode ser muito melhor compreendida pelo conceito de imagem-coisa. De mesmo modo, a representação desfalca a experiência destes indivíduos diante das imagens, experiência esta que pode ser muito melhor traduzida por meio do conceito de imagem-corpo, que coloca um parâmetro específico de compreensão da imagem no mundo, bastante distante da ideia de contemplação que estamos acostumados desde o Iluminismo para a apreciação artística.

\section{Considerações finais}

Por meio deste breve artigo, procuramos explorar questões concernentes às especificidades das fontes iconográficas medievais, destacando seus domínios materiais, visuais e imateriais. Considerando os aspectos levantados em torno dos usos e da recepção da imagem medieval dentro do período em que foi concebida, defendemos, ao longo do artigo, a utilização do conceito de imagem-corpo em detrimento de representação.

A imago medieval desvela-se como um objeto complexo, multifacetário, que deve ser analisado de modo minucioso e sem generalizações, sempre atento ao mundo que integra, pois a iconografia cristã não é apenas representação imagética, mas um elemento performático, quase mágico, sendo elemento sacramental, uma revelação do conhecimento e 
de Deus, um veículo de comunicação com o divino, digno de receber proskynesis ${ }^{10}$, mas jamais latria ${ }^{11}$, que deve ser reservada apenas para Deus (HOWES, 2007). A imagem, como vimos, se configura no mundo físico, assim como no mundo dos sonhos, não possuindo graus de diferenciação entre si, mas se configurando como formas de imagens de mesmo grau hierárquico. Todavia, os significados atribuídos às mais variadas imagens se modificam sim, pelo seu meio material, pela sua disposição espacial e pelos elementos que a compõe no ambiente, principalmente pelo caráter alegórico da iconografia medieval. Variados fenômenos acabam, assim, gerando diversos significados para uma mesma imagem. Portanto, é necessário um alto grau de especificidade teórico-metodológica para que um medievalista possa gerar alguma conclusão a respeito das fontes visuais no medievo.

Considerando as muitas significações que o termo representações adquiriu nas pesquisas historiográficas, e a necessidade de especificação para análise da imago medieval (que pode gerar muitos significados se não analisada de forma precisa), considerando a natureza da imagem no próprio medievo, consideramos pertinente o uso do conceito de imagem-corpo em detrimento do conceito de representação. Principalmente pelo fato do conceito de imagem-corpo pensar em uma definição para a imagética medieval que concentra os fenômenos de sua recepção, que extrapolam o que consideramos contemporaneamente como representação.

Como historiadores possuímos um compromisso com nossa fonte de pesquisa no ato de sua interpretação. Parte deste compromisso é a busca das ferramentas de análise mais adequadas para a natureza deste objeto. Embora o conceito de representação sirva para responder a muitas questões, inclusive de trabalhos do campo da medievalística, argumentamos que para a análise de fontes iconográficas e materiais, este não seja o caminho mais adequado.

\section{Referências}

\footnotetext{
${ }^{10}$ De origem grega "proskynesis" ( $\left.\pi \rho \circ \sigma \kappa v ́ v \eta \sigma \iota \varsigma\right)$ define um ato de prostrar-se diante de alguém em condições sociais superiores, que se dava por uma série de atitudes relacionadas aos diferentes níveis sociais. Na igreja católica, define a veneração diante das relíquias, ícones e santos.

${ }^{11}$ Do grego "latria" $(\lambda \alpha \tau \rho \varepsilon \imath \alpha)$ é um termo utilizado pela Igreja Católica que se refere ao amor excessivo e adoração, que deve ser dedicado de forma exclusiva a Deus.
} 
BALL, P. Universe of Stone: A biography of Chartres Cathedral. New York e Londres: Harper Perennial, 2009.

BASCHET, J. Images ou idoles? Annales Économies, Sociétés, Civilisations, v. 46, n. 2, p. 347-352, 1991.

BASCHET, J. Introdução: a imagem-objeto. In: SCHMITT, J.-C.; BASCHET, J. L'image: Fonctions et usages des images dans l'Occident médiéval. Tradução Maria Cristina Pereira. ed. Paris: Le Léopard d'Or, 1996. p. 7-26.

BASCHET, J. Introduction: L'image-objet. International Workshop on Medieval Societies. Paris: Le Léopard d'or. 1996. p. 7-26.

BASCHET, J. L'iconographie médiévale. Paris: Gallimard, 2008.

BASCHET, J.; DITTMAR, P.-O. Les images dans l'Occident médiéval. 1'a ed. Turnhout: Brepols, 2015.

BESANÇON, A. Arte e Cristianismo. In: FABRIS, A.; KERN, M. L. B. Imagem e Conhecimento. São Paulo: Editora da Universidade de São Paulo, 2006. p. 31-53.

BURKE, P. Testemunha Ocular: História e Imagem. São Paulo: EDUSC, 2004.

CHARTIER, R. À beira da falésia: a história entre incertezas e inquietude. Porto Alegre: Ed. Universidade UFRGS, 2002.

ECO, U. Arte e Beleza na Estética Medieval. Rio de Janeiro: Editora Globo, 1989.

KNAUSS, P. O Desafio de fazer História com Imagens: arte e cultura visual. ArtCultura, Uberlândia, 8, jan/jun 2006. 97-115.

MAKOWIECKY, S. Representação: a palavra, a ideia, a coisa. Cadernos de Pesquisa Interdisciplinar em Ciências Humanas, v. 57, p. 2-25, Dezembro 2003.

NIEHR, K. Sculpturing Architecture, Framing Sculpture, and Modes of Contextualizing the Arts in the Eleventh and Twelfth Centuries. In: MAXWELL, R. A.; AMBROSE, K. Current Directions in Eleventh and Twelfth Century Sculpture Studies. Turnhout: Brepols, 2010. p. 119-140.

PEREIRA, M. C. Uma arqueologia da História das Imagens. In: GOLINO, W. A importância da teoria para a produção artística e cultural. Vitória: [s.n.], 2006. p. 1-10. Disponivel em: <http://www.tempodecritica.com/link020122.htm>.

PEREIRA, M. C. Algumas questões sobre arte e imagens no Ocidente Medieval. In: VIII Ciclo de estudos antigos e medievais e IX Jornada de estudos antigos e medievais. Rio de Janeiro: Programa de Estudos Medievais, v. Atas Eletrônicas da VIII Semana de Estudos Medievais do Programa de Estudos Medievais da UFRJ - Edição Especial, 2010. p. 1-29.

PEREIRA, M. C. Exposition des ymages des figures qui sunt: discursos sobre imagens no Ocidente medieval. Antíteses, Londrina, 9, 2016. 30-54.

PEREIRA, M. C. Pensamento em imagem. Montagens topo-lógicas no claustro de Moissac. $1^{\mathrm{a}}$. ed. São Paulo: Intermeios, 2016. 
PEREIRA, M. C. Pensar (com) a imagem: reflexões teóricas para uma práxis historiográfica. Topoi (online): revista de História, 17, 2016. 672-679.

ROCHA, C. Arte: um desafio para Clio. O Olho da História, Salvador, v. 16, julho 2011.

SANTOS, C. A. Á. Alegoria, Iconografia, Iconologia. Seminário de História da Arte, Pelotas, V. 4, 2014. 1-38.

SCHMITT, J.-C. Imagens. In: GOFF, J. L.; SCHMITT, J.-C. Dicionário Temático do Ocidente Medieval. São Paulo: Edusc, v. 1, 2006. p. 591-605.

SCHMITT, J.-C. O Corpo das Imagens: ensaios sobre a cultura visual na Idade Média. São Paulo: EDUSC, 2007. 